\title{
Neonatal Hyperbilirubinemia - Early Detection with Umbilical Cord Blood Bilirubin and Umbilical Cord Blood Alkaline Phosphatase Levels - Individual vs Combined Predictive Markers
}

\author{
Rohit Singh ${ }^{1}$, Tiwari A. $\mathrm{K}^{2^{*}}$, Narang $\mathrm{S}^{3}$
}

${ }^{1}$ Senior Resident, Department of Pediatrics, ${ }^{2}$ Senior Consultant, Department of Pediatrics, ${ }^{3}$ Senior Consultant, Department of Radiology, Mata Chanan Devi Hospital, c1, Lal Sai Mandir Marg, Block C1, Janakpuri, New Delhi, Delhi 110058, India

*Corresponding author: Ajay Kumar Tiwari

\section{Abstract}

Background: To assess the significance of umbilical cord blood alkaline phosphatase and umbilical cord blood bilirubin as a combined marker for prediction of neonatal hyperbilirubinemia. Methods: The present study was conducted in department of Pediatrics, Mata Chanan Devi Hospital, Janakpuri, New Delhi between march 2018 to september 2019 included 370 healthy full term newborns fulfilling inclusion and exclusion criteria. The cord blood alkaline phosphatase level and cord blood bilirubin level were measured at birth. All the neonates were clinically observed for the development of jaundice for 5 days and serum bilirubin level estimation was done as and when required. Significant hyperbilirubinemia was considered when serum bilirubin level in term newborns was more than or equal to $12 \mathrm{mg} / \mathrm{dl}$ at $24 \mathrm{hrs}$ of life, $15 \mathrm{mg} / \mathrm{dl}$ at $48 \mathrm{hrs}$, and $17 \mathrm{mg} / \mathrm{dl}$ at $72 \mathrm{hrs}$. Results: Out of 370 cases, 58 neonates developed significant hyperbilirubinemia i:e 16\%. 28 babies had ABO incompatibility out of which 11 had significant hyperbilirubinemia $(\mathrm{p}=0.002)$ and 23 babies had RH incompatibility out of which 11 developed significant hyperbilirubineia $(\mathrm{p}<0.001)$. Mean \pm SD cord blood bilirubin level in no significant hyperbilirubinemia group and significant hyperbilirubinemia group was $1.63 \pm 0.44 \mathrm{mg} / \mathrm{dl}$ and $2.49 \pm 0.22 \mathrm{mg} / \mathrm{dl}$ respectively with statistical analysis $(\mathrm{p}<0.001)$. There is no significant difference of cut off value of cord ALP level at 140.5 IU/L between significant and non significant hyperbilirubinemia group ( $\mathrm{p}=0.398$ ). Among Neonates with significant hyperbilirubinemia 55.18\% were having cord blood bilirubin level $>2.205 \mathrm{mg} / \mathrm{dl}$ and cord blood ALP level $>140.5 \mathrm{IU} / \mathrm{L}$, in remaining $44.82 \%$ the cord blood bilirubin level was $\leq 2.205$ $\mathrm{mg} / \mathrm{dl}$ and cord blood ALP level was $\leq 140.5 \mathrm{IU} / \mathrm{L}$ and combined statistical analysis showed significant neonatal hyperbilirubinemia $(\mathrm{p}<0.001)$. Conclusions: Our study showed no significant association between cord blood ALP level and neonatal hyperbilirubinemia. Optimum cut off level of umbilical cord blood bilirubin was $2.205 \mathrm{mg} / \mathrm{dl}$ with high sensitivity $(91.4 \%)$ and specificity $(94.9 \%)$ to predict significant neonatal hyperbilirubinemia with positive predictive value was $76.8 \%$ and the negative predictive value was $98.3 \%$. Combined cord blood alkaline phosphatase (cut off level $140.5 \mathrm{IU} / \mathrm{L}$ ) and cord blood bilirubin (cut off level $2.205 \mathrm{mg} / \mathrm{dl}$ ) showed significant association with neonatal hyperbilirubinemia $(\mathrm{p}<0.001)$ with sensitivity of $55.2 \%$, increase in specificity to $97.1 \%$ and also slight increase in positive predictive value to $78 \%$. Combined negative predictive value of cord blood blirubin and alkaline phosphatase is $92.1 \%$.

Keywords: Neonatal hyperbilirubinemia, umbilical cord blood alkaline phosphatase, umbilical cord blood bilirubin.

Copyright @ 2020: This is an open-access article distributed under the terms of the Creative Commons Attribution license which permits unrestricted use, distribution, and reproduction in any medium for non-commercial use (NonCommercial, or CC-BY-NC) provided the original author and source are credited.

\section{INTRODUCTION}

Worldwide neonatal hyperbilirubinemia is one of the major issues in clinical practice. Most of the newborns have mild jaundice but all the newborns should be carefully monitored because of the potential toxicity of bilirubin. Severe untreated neonatal hyperbilirubinemia can lead to acute bilirubin encephalopathy [1]. When serum bilirubin in term newborn reaches the level of $\geq 12 \mathrm{mg} / \mathrm{dl}$ at $24 \mathrm{hrs}$ of life, $15 \mathrm{mg} / \mathrm{dl}$ at $48 \mathrm{hrs}$, and $17 \mathrm{mg} / \mathrm{dl}$ at $72 \mathrm{hrs}$ then it is called significant neonatal hyperbilirubinemia [2]. Early discharge of healthy term newborns after delivery has become a common practice now a days because of multi factorial reasons mainly medico-social and economic, and also early discharge is the main culprit for late diagnosis of neonatal hyperbilirubinemia. Discharged babies need to be followed up for next 2 to 3 days for assessment of developing hyperbilirubinemia. However, follow ups are not up to the mark due to patients non compliance. Newborns 
discharged before 72 hours after birth had significant risk of readmission with hyperbilirubinemia [3].

Prompt treatment of hyperbilirubinemia is crucial, as well as assessment of the risk of development of hyperbilirubinemia. Thus, the investigation of parameters that might help in predicting the development of significant hyperbilirubinemia is justifiable and necessary.

Over the years many efforts have been made to identify the newborns likely to develop severe hyperbilirubinemia. Various strategies have been studied in order to reduce the duration of hospital stay for normal babies and identify those who may need prior treatment before developing bilirubin encephalopathy. Follow up within 1-2 days of early discharge; umbilical cord bilirubin levels; routine predischarge serum bilirubin levels; transcutaneous bilirubin measurement and clinical assessment of risk factors of jaundice are various strategies to predict significant hyperbilirubinemia [3].

The aim of the present study was to see the significance of cord blood alkaline phosphatase level and cord blood bilirubin level as a combined predictor of neonatal hyperbilirubinemia.

\section{MATERIALS AND METHODS}

The present study was conducted in department of Pediatrics, Mata Chanan Devi Hospital, Janakpuri, New Delhi between march 2018 to september 2019. Study subjects included 370 healthy full term newborns fulfilling inclusion and exclusion criteria.

\section{Inclusion Criteria}

- Gestational age more than 37 weeks

- $\quad$ Birth weight $>2500$

- Both genders

- From any mode of delivery

- Apgar score of more than 7 at fifth minutes of life

\section{Exclusion Criteria}

- Newborns who later develop significant illness requiring NICU admission like

- Septicemia, meningitis ARDS etc

- Newborns with major congenital malformations.

- Conjugated hyperbilirubinemia

- $\quad$ Birth weight less than 2500 grams

Newborns were included in study after explaining the study to parents and written informed consent was taken from the parents. The study was approved by ethical and scientific committee of mata chanan devi hospital.
The cord blood alkaline phosphatase level and cord blood bilirubin level were measured at birth. All the neonates were clinically observed for the development of jaundice for 5 days and serum bilirubin level estimation was done as and when required on clinical evaluation. The ALP estimation was done by measuring the rate of conversion of p-nitrophenolphosphate (pNPP) to p-nitrophenol (pNP) in presence of magnesium and zinc ions and of 2-amino-2methyl-1-propanol (AMP) as phosphate acceptor at $\mathrm{PH}$ 10.4. The rate of change in absorbance due to formation of pNP is measured bichromatically at $410 / 480 \mathrm{~nm}$ and is directly proportional to ALP activity in the sample by Beckman coulter AU270. The cord and serum bilirubin estimation was done using - a photometric method on Beckman coulter AU480 for estimation of direct and total bilirubin.

\section{STATISTICAL ANALYSIS}

Categorical variables presented in number and percentage $(\%)$ and continuous variables were presented as mean \pm SD. Normality of data tested by Kolmogorov-Smirnov test.

Statistical tests applied as follows-

- Qualitative variables compared using ChiSquare test /Fisher's exact test.

- $\quad$ t-test to compare mean values between the two groups was used.

- $\quad$ ROC used to find the cutoff values, sensitivity and specificity was also calculated.

- Pearson correlation was used to see the relationship between the two variables.

$\mathrm{P}$-value less than 0.05 considered as significant at $95 \%$ confidence level. The statistical software SPSS version 24.0 was used in the analysis.

\section{RESULTS}

We enrolled 370 healthy term newborns with birth weight of more than 2500 gram. In our study out of 370 cases, 200 were males (54\%) and $170(46 \%)$ were females.

Out of 370 cases, 58 newborns developed significant hyperbilirubinemia. Incidence of significant hyperbilirubinemia in this study was $16 \%$.

The majority of the cases that is 225 babies in our study belonged to birth weight group of $<3 \mathrm{~kg}$ while 145 cases were from $3-4 \mathrm{~kg}$ group. Mean \pm SD Birth weight are $2.99 \pm 0.35 \mathrm{~kg}$ and $2.95 \pm 0.31 \mathrm{~kg}$ in no significant hyperbilirubinemia group and significant hyperbilirubinemia respectively showing no significance $\mathrm{p}=0.442$.

232 newborns were born at a gestation of $\leq 38$ weeks and 138 newborns were born at a gestation of $>38$ weeks. Mean \pm SD gestational age is $38.35 \pm 0.92$ in no significant hyperbilirubinemia and $38.20 \pm 0.96$ 
weeks in significant hyperbilirubinemia showing no significance $\mathrm{p}=0.26$.

We found no significant association between the cases who did and who did not develop significant hyperbilirubinemia with respect to various factors such as gender and parity with value $P>0.05$. (Table- 1 )

In this study hyperbilirubinemia was significantly associated with the presence of maternalfetal blood group incompatibility $(\mathrm{p}=0.002$ for $\mathrm{ABO}$ incompatibility and $\mathrm{p}<0.001$ for $\mathrm{Rh}$ incompatibility). Out of 370 newborns, 28 cases had ABO (O-A or O-B) incompatibility and 23 cases had Rh incompatibility. In neonates with $\mathrm{ABO}$ incompatibility 11 cases had significant hyperbilirubinemia, in case of $\mathrm{Rh}$ incompatibility 11 developed significant hyperbilirubinemia.

Mean \pm SD cord blood bilirubin level in no hyperbilirubinemia group and hyperbilirubinemia group was $1.63 \pm 0.44 \mathrm{mg} / \mathrm{dl}$ and $2.49 \pm 0.22 \mathrm{mg} / \mathrm{dl}$ respectively.
There was significant association between cord blood bilirubin level and hyperbilirubinemia $(\mathrm{p}<0.001)$.

Among Neonates with significant hyperbilirubinemia $91.37 \%$ were having cord blood bilirubin level $>2.205 \mathrm{mg} / \mathrm{dl}$ and in remaining $8.62 \%$ the cord blood bilirubin level was $\leq 2.205 \mathrm{mg} / \mathrm{dl}$. While in neonates with no significant hyperbilirubinemia $94.87 \%$ were having cord blood bilirubin level $\leq 2.205$ $\mathrm{mg} / \mathrm{dl}$ and only $5.12 \%$ were having cord blood bilirubin level $>2.205 \mathrm{mg} / \mathrm{dl}(\mathrm{p}<0.001)$.

In this study receiver operating characteristic (ROC curve) (Figure-1) analysis demonstrates that cord blood bilirubin $>2.205$ had the high sensitivity $(91.4 \%)$ and specificity $(94.9 \%)$ to predict the newborn that would develop significant hyperbilirubinemia with area under curve 0.97. At this level the positive predictive value was $76.8 \%$ and the negative predictive value was $98.3 \%$. So optimum cut off level for prediction of significant neonatal hyperbilirubinemia using umbilical cord blood bilirubin was $2.205 \mathrm{mg} / \mathrm{dl}$.

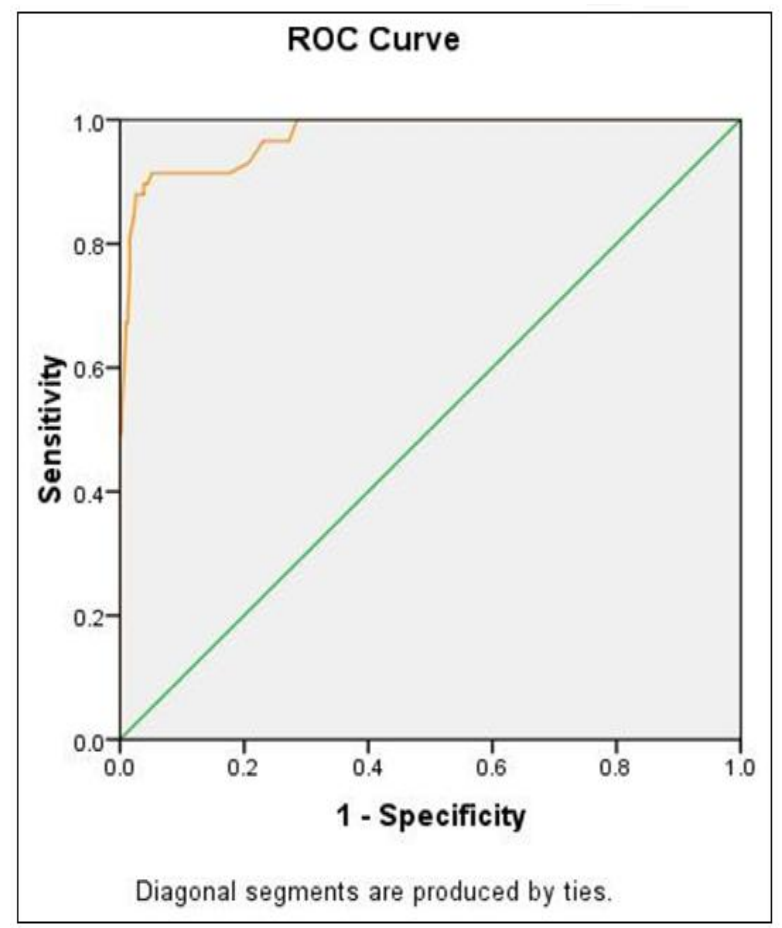

Fig-1: Receiver operating characteristic curve for cord blood bilirubin

We did not find significant association between cord blood ALP levels between significant hyperbilirubinemia and no significant hyperbilirubinemia $(\mathrm{p}=0.807)$.

In this study mean ALP in no significant hyperbilirubinemia group is $157.21 \pm 59.83 \mathrm{IU} / \mathrm{L}$ while mean ALP in significant hyperbilirubinemia group is $155.19 \pm 44.40 \mathrm{IU} / \mathrm{L}(\mathrm{p}=0.807)$ which is not significant.
In this study we found optimum cord ALP cut off level at 140.5 IU/L. Receiver operating characteristic (ROC curve) (Figure-2) analysis demonstrates that cord blood ALP >140.5 IU/L had the low sensitivity $(62.1 \%)$ and specificity $(43.9 \%)$ to predict the new born that would develop significant hyperbilirubinemia with area under curve 0.51 . At this level the positive predictive value was $17.1 \%$ and the negative predictive value was $86.2 \%$ 


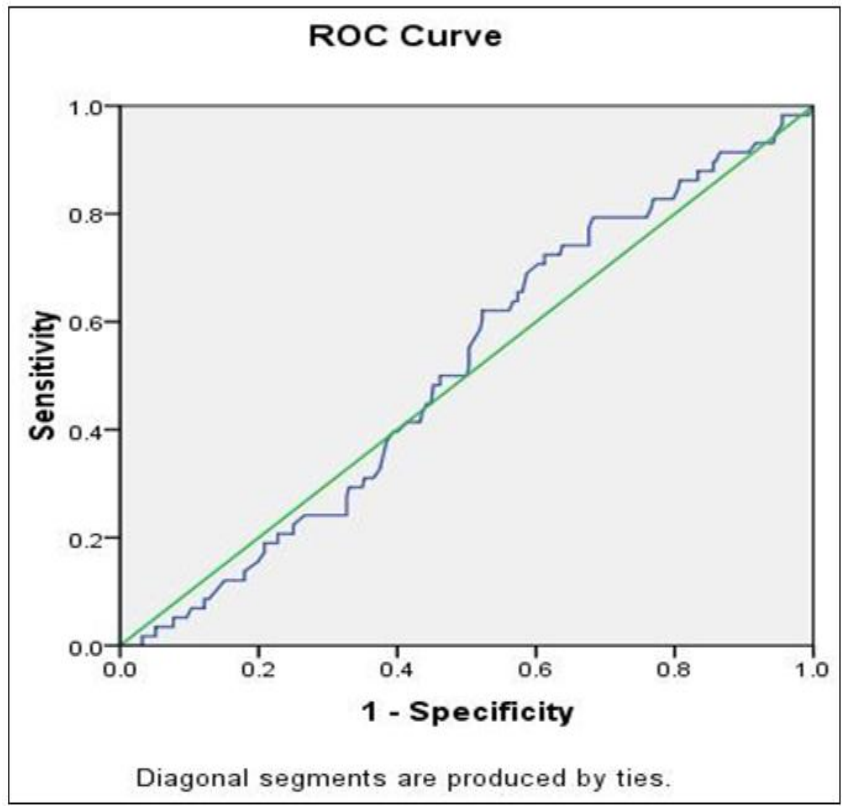

Fig-2: Receiver operating characteristic curve for cord blood ALP

Among neonates with significant hyperbilirubinemia $55.18 \%$ were having cord blood bilirubin level $>2.205 \mathrm{mg} / \mathrm{dl}$ and cord blood ALP $>140.5$ IU/L, in remaining $44.82 \%$ the cord blood bilirubin level was $\leq 2.205 \mathrm{mg} / \mathrm{dl}$ and cord blood ALP was $\leq 140.5 \mathrm{IU} / \mathrm{L}$. While in neonates with no significant hyperbilirubinemia $97.11 \%$ were having cord blood bilirubin level $\leq 2.205 \mathrm{mg} / \mathrm{dl}$ and cord blood ALP $\leq 140.5 \mathrm{IU} / \mathrm{L}$. In this study combined cord blood alkaline phosphatase and cord blood bilirubin levels had a significant association with neonatal hyperbilirubinemia $(\mathrm{p}<0.001)($ Table-1).

The combined cord blood bilirubin (cut off level $2.205 \mathrm{mg} / \mathrm{dl}$ ) and cord blood alkaline phosphatase (cut off level 140.5 IU/L), ROC curve (Figure-3) demonstrate a fall in sensitivity $(55.2 \%)$ compared to cord blood bilirubin individually (sensitivity of $91.4 \%$ ). But there is increase in specificity to $97.1 \%$ and also slight increase in positive predictive value to $78 \%$. Combined negative predictive value of cord blood blirubin and alkaline phosphatase is $92.1 \%$.

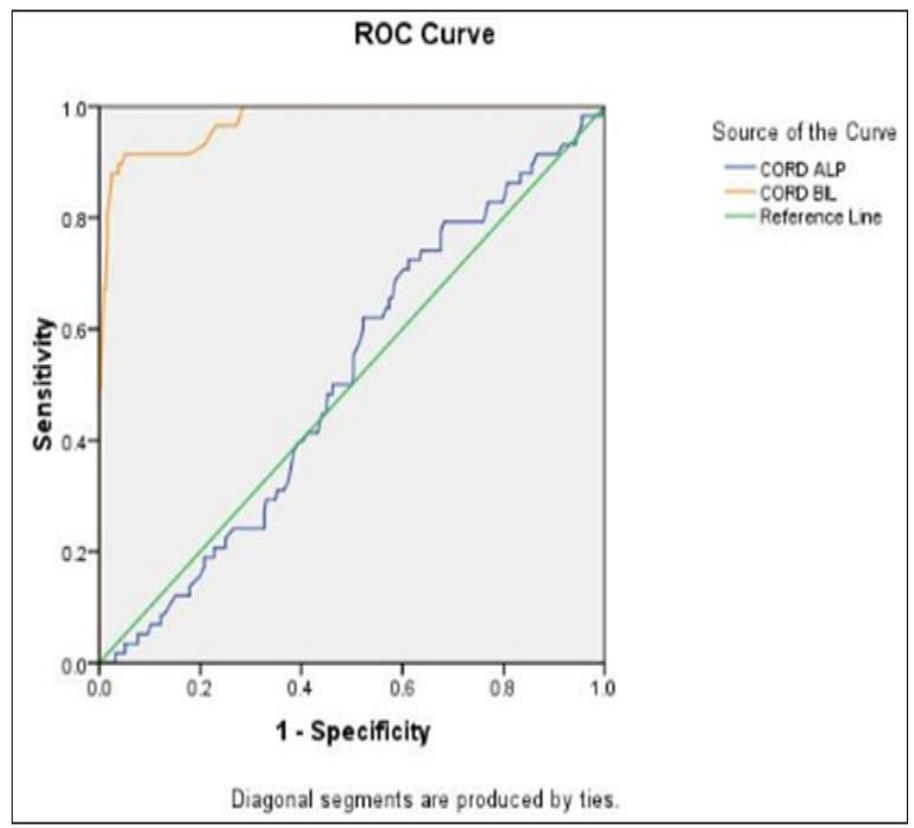

Fig-3: Receiver operating characteristic curve for combined cord blood bilirubin and ALP 
Table-1: Relationship between various factors with hyperbilirubinemia in our study

\begin{tabular}{|l|l|l|l|}
\hline Variable & $\begin{array}{l}\text { No } \\
\text { hyperbilirubinemia }\end{array}$ & $\begin{array}{l}\text { Significant } \\
\text { Hyperbilirubinemia }\end{array}$ & P value \\
\hline Gender: male/female & $171 / 141$ & $29 / 29$ & 0.5 \\
\hline Mean Birth weight (kg) & $2.99 \pm 0.35$ & $2.95 \pm 0.31$ & 0.442 \\
\hline Mean Gestational age (weeks) & $38.35 \pm 0.92$ & $38.20 \pm 0.96$ & 0.26 \\
\hline $\begin{array}{l}\text { Blood group incompatibility No ABO/No Rh/ ABO/Rh } \\
\text { incompatibility }\end{array}$ & $235 / 243 / 17 / 12$ & $44 / 44 / 11 / 11$ & $\mathbf{0 . 0 0 2}$ and \\
\hline Mean Cord ALP level (IU/L) & $157.21 \pm 59.83$ & $155.19 \pm 44.40$ & 0.807 \\
\hline Cut of value of cord blood ALP (>140.5 IU/L) & 175 out of 312 & 36 out of 58 & 0.398 \\
\hline Mean cord blood bilirubin level (mg/dl) & $1.63 \pm 0.44$ & $2.49 \pm 0.22$ & $<\mathbf{0 . 0 0 1}$ \\
\hline Cut of value of cord blood bilirubin (>2.205 mg/dl) & 16 out of 312 & 53 out of 58 & $<\mathbf{0 . 0 0 1}$ \\
\hline $\begin{array}{l}\text { Combined comparison at cut off value of cord blood } \\
\text { bilirubin at }>2.205 m g / d l \text { and cord blood ALP at >140.5 } \\
\text { IU/L }\end{array}$ & 9 out of 312 & 32 out of 58 & $<\mathbf{0 . 0 0 1}$ \\
\hline
\end{tabular}

\section{DISCUSSION}

Hyperbilirubinemia is the most prevalent complication during the neonatal period. The native bilirubin is toxic and is capable of passing the bloodbrain barrier due to its lipophilicity. If the level exceeds the neuroprotective defense mechanism, it can result in acute bilirubin encephalopathy.

Aktas S et al., [4] 2019 aimed to investigate whether cord blood bilirubin (CBB) level could be used to identify the newborns at a high risk of developing hyperbilirubinemia. The cutoff value of $\mathrm{CBB}$ for predicting the occurrence of significant hyperbilirubinemia requiring phototherapy was 1.67 $\mathrm{mg} / \mathrm{dL}$, with a sensitivity of $82 \%$ and specificity of $53 \%$. They concluded that CBB could be useful to determine newborns at a risk of developing hyperbilirubinemia and prevent developing severe complications due to delay in diagnosis.

Garg A et al., [5] 2017 concluded that there was positive correlation between umbilical cord blood bilirubin level and significant hyperbilirubinemia. They found that cutoff umblilical cord blood bilirubin level of $2.2 \mathrm{mg} / \mathrm{dl}$ in healthy term neonate can predict significant hyperbilirubinemia with sensitivity of $92.6 \%$ and specificity of $90.6 \%$.

Mayank Pahuja et al., [6] 2016 study was conducted on 100 term healthy neonates delivered at tertiary care hospital. Cord blood bilirubin level of more $>1.87 \mathrm{mg} / \mathrm{dl}$ can reliably predict neonatal hyperbilirubinemia $(61.3 \%$ sensitive and $76.8 \%$ specific) in healthy term neonates.

Calkins K et al., [7] 2015 did a study to demonstrate the predictive ability of cord blood bilirubin $(\mathrm{CBB})$ for hyperbilirubinemia in a population at risk for maternal-fetal blood group incompatibility and haemolytic disease of the newborn. When compared to controls, cases had a higher mean $( \pm \mathrm{SD})$ CBB $(2.5 \pm 0.5$ vs. $1.8 \pm 0.4 \mathrm{mg} / \mathrm{dL}, \mathrm{p}<0.001)$, the mean $\mathrm{CBB}$ concentration was higher in neonates who received phototherapy compared to those who did not.
They concluded CBB concentration may help predict severe hyperbilirubinemia and phototherapy in a population at risk for haemolytic disease of the newborn.

Eshwara Chary et al., [8] 2014 conducted study to identify the newborns at risk for developing significant hyperbilirubinemia using cord blood serum bilirubin levels. $18.09 \%$ healthy term newborns developed significant hyperbilirubinemia. In their study on the amount of umbilical cord bilirubin cut off point of $2 \mathrm{mg} / \mathrm{dl}$ had good sensitivity (94.12), specificity (90.9\%), positive predictive value (69.57\%) and negative predictive value $(98.59 \%)$.

Alaaeldin A. Zeitoun et al., [9] 2013 found that the cord blood total serum bilirubin level is indicative of jaundice severity developed in healthy full term and late preterm newborns without complications. The cutoff for total cord bilirubin level in preterm and full term babies is 2.05 and $2.15 \mathrm{mg} / \mathrm{dl}$ respectively.

Nagwa hamdi et al., [10] 2012 in their study on healthy full-term and near term concluded that measurement of umbilical cord serum bilirubin level can be used as a screening tool for predicting the development of significant hyperbilirubinemia requiring interventional therapy. Levels of umbilical cord serum bilirubin equal to or greater than $2 \mathrm{mg} / \mathrm{dl}$ in term and near term newborns indicated 91 percent probability for the requirement of phototherapy.

In our study, there was significant association between cord blood bilirubin level and hyperbilirubinemia $(\mathrm{p}<0.001)$. We found cord blood bilirubin $>2.205$ had the high sensitivity (91.4\%) and specificity $(94.9 \%)$ to predict the newborn that would develop significant hyperbilirubinemia. At this level the positive predictive value was $76.8 \%$ and the negative predictive value was $98.3 \%$.

Hannan Mohamed et al., [11] 2019 the study included 100 newborns with gestational age more than $35 \mathrm{wk}$. They concluded that cord blood alkaline 
phosphatase level is not only a useful predictor for severe neonatal jaundice but also can predict the early onset of neonatal hyperbilirubinemia and expected methods of treatment in healthy newborns more than 35 weeks gestational age.

Al Assal et al., [12] 2017 did a study in which a total of 200 healthy full term babies with apparently healthy mothers were evaluated and investigated for ALP assay and follow up the level of serum billirubin. ALP levels were significantly higher in babies requiring therapy such as phototherapy or exchange transfusion. The best cut off point for serum ALP to predict neonates needed treatment of neonatal jaundice was found $>315$ with sensitivity $84.2 \%$ and specificity of $84.48 \%$ and area under curve $88.8 \%$, they concluded that cord blood ALP levels may be a significant predictor of developing hyperbilirubinemia requiring treatment.

In 2015 Mousa Ahmadpour-Kacho et al., [13] did the study to find a relation between cord blood alkaline phosphatise and newborn who develop neonatal hyperbilirubinemia. Study shows a significant result when cord blood alkaline phosphatase and serum bilirubin where compared with $\mathrm{p}$ value 0.041 and cut off value $>314$ IU/L associated with $80 \%$ sensitivity and $63 \%$ specificity.

We did not find significant association between cord blood ALP levels and significant hyperbilirubinemia $(p=0.807)$. In our study we found optimum cord ALP cut off level at $140.5 \mathrm{IU} / \mathrm{L}$. At this level, sensitivity $(62.1 \%)$ and specificity $(43.9 \%)$ was low to predict the newborn that would develop significant hyperbilirubinemia. At this level the positive predictive value was $17.1 \%$ and the negative predictive value was $86.2 \%$.

When we combine cord blood bilirubin (cut off level $2.205 \mathrm{mg} / \mathrm{dl}$ ) and cord blood alkaline phosphatase (cut off level 140.5 IU/L), sensitivity $(55.2 \%)$ value decreases but specificity increases $(97.1 \%)$ and there is also increase in positive predictive value to $78 \%$. The negative predictive value is $92.1 \%$ (Table-2).

Table-2: Comparison between cord blood ALP, cord blood bilirubin and combined cord blood ALP and bilirubin parameters in our study

\begin{tabular}{|l|l|l|l|}
\hline & CORD ALP & CORD BILIRUBIN & COMBINED CORD BLOOD ALP AND BILIRUBIN \\
\hline SENSITIVITY & $\mathbf{6 2 . 1 \%}$ & $\mathbf{9 1 . 4 \%}$ & $55.2 \%$ \\
\hline SPECIFICITY & $\mathbf{4 3 . 9 \%}$ & $\mathbf{9 4 . 9 \%}$ & $\mathbf{9 7 . 1 \%}$ \\
\hline PPV & $17.1 \%$ & $\mathbf{7 6 . 8 \%}$ & $\mathbf{7 8 \%}$ \\
\hline NPV & $\mathbf{8 6 . 2 \%}$ & $98.3 \%$ & $\mathbf{9 2 . 1 \%}$ \\
\hline
\end{tabular}

\section{CONCLUSION}

Umbilical cord blood alkaline phosphatase individually is not a good screening tool for predicting the development of neonatal hyperbilirubinemia.

Umbilical cord blood bilirubin individually can be used as a screening tool for development of neonatal hyperbilirubinemia. Cutoff umbilical cord blood bilirubin level of $2.205 \mathrm{mg} / \mathrm{dl}$ in healthy term neonate can predict significant hyperbilirubinemia with high sensitivity and specificity.

Combining cord blood alkaline phosphatase and cord blood bilirubin levels improves specificity and positive predictive value for detection of neonatal hyperbilirbinemia and hence cord blood alkaline phosphatase levels and cord blood bilirubin levels can be used in combination as screening tests for development of significant neonatal hyperbilirubinemia.

Babies with blood group incompatibility should be closely monitored for significant hyperbilirubinemia.

More studies are needed on this topic with higher sample size for further evaluation.
So we conclude combined cord blood alkaline phosphatase and cord blood bilirubin levels have a significant positive correlation in predicting neonatal hyperbilirubinemia.

\section{REFERENCES}

1. Radmacher, P. G., Groves, F. D., Owa, J. A., Ofovwe, G. E., Amuabunos, E. A., Olusanya, B. O., \& Slusher, T. M. (2015). A modified Bilirubin-induced neurologic dysfunction (BINDM) algorithm is useful in evaluating severity of jaundice in a resource-limited setting. BMC pediatrics, 15(1), 28.

2. Ambalavanan, N., \& Carlo W. A. (2015). Jaundice and Hyperbilirubinemia in the Newborn Kliegman, R. M., Behrman, R. E., Jenson, H. B., Stanton, B. M. Nelson textbook of pediatrics. 20th edition. Philadelphia, PA. Elsevier Health Sciences; 871-875.

3. Ahire N, Sonawane R, Gaikwad R, Patil S, Sonawane T. Study of Correlation of Cord Blood Bilirubin with Neonatal Hyperbilirubinemia. MVP Journal of Medical Sciences. 2016 Feb 29;3(1):606.

4. Aktas, S., Dogan, C., Okmen, Z. H., \& Gulec, S. G. (2019). Is Cord Blood Bilirubin Level a Reliable Predictor for Developing Significant 
Hyperbilirubinemia?. American journal of perinatology, 36(03), 317-321.

5. Garg, A., Tiwari, A. K., \& Narang, S. (2017). Umbilical Cord Bilirubin-an Early Diagnostic Marker of Significant Neonatal Hyperbilirubinemia. JMSCR, 05(4); 20345-20349.

6. Pahuja, M., Dhawan, S., \& Chaudhary, S. R. (2016). Correlation of cord blood bilirubin and neonatal hyperbilirubinemia in healthy newborns. International Journal of Contemporary Pediatrics, 3(3), 926.

7. Calkins, K., Roy, D., Molchan, L., Bradley, L., Grogan, T., Elashoff, D., \& Walker, V. (2015). Predictive value of cord blood bilirubin for hyperbilirubinemia in neonates at risk for maternal-fetal blood group incompatibility and hemolytic disease of the newborn. Journal of neonatal-perinatal medicine, 8(3), 243-250.

8. Chary, E., Bharadwaj, N., Kumar, P., Vivekand, N., Sailaja, V., \& Harika, B. (2014). Umbilical cord blood bilirubin level measurement in predicting the development of significant hyperbilirubinemia. Indian Journal of Mednodent and Allied Sciences, 2(2), 144-148.
9. Zeitoun, A. A., Elhagrasy, H. F., \& Abdelsatar, D. M. (2013). Predictive value of umbilical cord blood bilirubin in neonatal hyperbilirubinemia. Egyptian Pediatric Association Gazette, 61(1), 23-30.

10. Hamdi, N., Elgayar, A., \& Salah, M. (2012). Cord blood bilirubin as a predictor of neonatal hyperbilirubinemia. The Medical Journal of Cairo University, 80(2).

11. Elmonem, A., Mohamed, H., Fakhr El-Din, A. R., Kholeef, E. F., \& Nasr Eldin, S. (2019). Alkaline phosphatase and haptoglobin as predictor of neonatal jaundice. The Egyptian Journal of Hospital Medicine, 74(5), 978-987.

12. Al Assal, H. M., Hablas, H. R., Afia, A. A. E., \& Khedr, M. A. A. Utility of Cord Blood Alkaline Phosphatase Enzyme as a Predictor of Significant Neonatal Jaundice in Well Term Infants.

13. Ahmadpour-Kacho, M., Pasha, Y. Z., Haghshenas, M., Rad, Z. A., Firouzjahi, A., Bijani, A., ... \& Baleghi, M. (2015). Cord blood alkaline phosphatase as an indicator of neonatal jaundice. Iranian journal of pediatrics, 25(5): $\mathrm{e}$ 718. 